\title{
Longitudinal Performance Assessment of Traffic Signal System Impacted by Long-Term Interstate Construction Diversion Using Connected Vehicle Data
}

\author{
Enrique D. Saldivar-Carranza, Margaret Hunter, Howell Li, Jijo Mathew, Darcy M. Bullock \\ Purdue University, West Lafayette, USA \\ Email: esaldiva@purdue.edu, hunter87@purdue.edu, howell-li@purdue.edu,kjijo@purdue.edu, darcy@purdue.edu
}

How to cite this paper: Saldivar-Carranza, E.D., Hunter, M., Li, H., Mathew, J. and Bullock, D.M. (2021) Longitudinal Performance Assessment of Traffic Signal System Impacted by Long-Term Interstate Construction Diversion Using Connected Vehicle Data. Journal of Transportation Technologies, 11, 644-659.

https://doi.org/10.4236/jtts.2021.114040

Received: August 7, 2021

Accepted: September 11, 2021

Published: September 14, 2021

Copyright $\odot 2021$ by author(s) and Scientific Research Publishing Inc. This work is licensed under the Creative Commons Attribution International License (CC BY 4.0).

http://creativecommons.org/licenses/by/4.0/

\begin{abstract}
Local arterials can be significantly impacted by diversions from adjacent work zones. These diversions often occur on unofficial detour routes due to guidance received on personal navigation devices. Often, these routes do not have sufficient sensing or communication equipment to obtain infrastructure-based traffic signal performance measures, so other data sources are required to identify locations being significantly affected by diversions. This paper examines the network impact caused by the start of an 18-month closure of the I-65/70 interchange (North Split), which usually serves approximately 214,000 vehicles per day in Indianapolis, IN. In anticipation of some proportion of the public diverting from official detour routes to local streets, a connected vehicle monitoring program was established to provide daily performances measures for over 100 intersections in the area without the need for vehicle sensing equipment. This study reports on 13 of the most impacted signals on an alternative arterial to identify locations and time of day where operations are most degraded, so that decision makers have quantitative information to make informed adjustments to the system. Individual vehicle movements at the studied locations are analyzed to estimate changes in volume, split failures, downstream blockage, arrivals on green, and travel times. Over 130,000 trajectories were analyzed in an 11-week period. Weekly afternoon peak period volumes increased by approximately $455 \%$, split failures increased $3 \%$, downstream blockage increased $10 \%$, arrivals on green decreased $16 \%$, and travel time increase $74 \%$. The analysis performed in this paper will serve as a framework for any agency that wants to assess traffic signal performance at hundreds of locations with little or no existing sensing or communication infrastructure to prioritize tactical retiming and/or longer-term infrastructure investments.
\end{abstract}




\section{Keywords}

Traffic Signal Performance Measures, Connected Vehicle, Longitudinal Study, Big Data

\section{Introduction}

Interstate maintenance and construction can significantly impact the surrounding network by creating an influx of diverging vehicles that can saturate local streets. This can lead to significant congestion and delays. According to the 2021 Urban Mobility Report [1], in 2019 there were 8.7 billion hours of congestion-related travel delay, which represented a $\$ 190$ billion cost in time and wasted fuel. The Federal Highway Administration (FHWA) indicates that 10\% of all congestion, and $24 \%$ of non-recurring congestion, are caused by work zones [2] [3]. Therefore, it is imperative for agencies to develop scalable monitoring tools that do not require infrastructure investments, to detect and mitigate the effects that work zones have on local streets.

\subsection{Literature Review}

There has been extensive research on driver behavior when presented with alternative routes by message signs [4] [5] [6] and by Advanced Traveller Information Services (ATIS) [7] [8], as well as stated surveys and modelling studies that analyze the impact of traffic on alternative routes [9] [10] [11] [12]. It is well understood at the macro model level, that diversions onto local streets will occur, but those models do not provide sufficient fidelity to characterize the daily, hourly, and even 15-minute variations in driver route choices that impact local streets.

Intelligent Transportation System (ITS) technology has been employed to assess the consequences of diversions. Bluetooth sensors have been used to identify driver route choices related to work zones [13] [14] [15]. In addition, agencies in Indiana have used traffic impact dashboards from vehicle probe data to assess mobility and queues during an unplanned 37-mile-long closure of an interstate [16].

State-of-the-practice Automated Traffic Signal Performance Measures (ATSPMs) utilize controller high-resolution data to provide insight on the efficiency of traffic signals [17] [18] [19]. However, this technology provides information on an intersection-by-intersection basis, relies on communication and sensing equipment, and requires significant initial capital investment [17]. With the emergence of commercially available Connected Vehicle (CV) trajectory data, new methods have been developed to generate traffic signal performance measures without the need for on-site infrastructure. Queue lengths can be estimated from CV data [20] [21]. Additionally, traditional travel times [22] [23], Highway Capacity Manual (HCM) Level of Service (LOS) [24] [25] [26] [27] [28], and arriv- 
als on green [25] [26] [27] [29] have also been calculated. Further, critical split failures and downstream blockage have also been derived from trajectory data [25] [26].

Even though traffic signal performance measures derived from CV trajectory data provide accurate results, do not depend on vehicle sending equipment, and improve scalability in comparison with ATSPMs, no studies have used this recently available dataset to assess the impact of long-term work zone diversions on local arterials.

\subsection{Motivation}

The motivation of this study is to demonstrate that current CV trajectory data can be integrated into real-time dashboards to assess the impact work zone diversion has on local streets. This is demonstrated using a case study based upon a 13-intersection segment impacted by a long-term closure of the I-65/70 interchange in Indianapolis. The case study performs a longitudinal analysis assessment of the changes in:

- Volumes;

- Split failures;

- Downstream blockage;

- Arrivals on green;

- And travel time.

\subsection{Study Contribution}

This study's main contribution is a framework which utilizes techniques that:

- Only use CV trajectory data to assess the effects of diversions on local arterials. This independence from infrastructure-based monitoring equipment makes the techniques very scalable for any agency that wants to assess in real-time the effects of diversions on local arterials;

- Allow practitioners to identify locations that are under-performing;

- Provide insight on the type of problem being experienced (saturation and/or coordination), which aids in the identification of potential solutions.

\section{Study Location}

The I-65/70 interchange located in downtown Indianapolis (Figure 1), also known as North Split, was closed on May 15th, 2021, and is planned to remain closed for another 18 months. The North Split usually serves approximately 214,000 vehicles per day. As this volume of vehicles utilizes local streets as detour, the overall network performance gets degraded.

Thirteen of the most affected intersections are studied. They are all located on West St, a parallel arterial to the North Split (Figure 1). Their names and allowed mainline direction of travel (southbound: SB, and northbound: NB) are shown in Table 1. It is important to mention that, as an outlier, intersection number 7 (West St @ Robert D. Orr Plaza) has a constant green light for vehicles traveling SB through. 


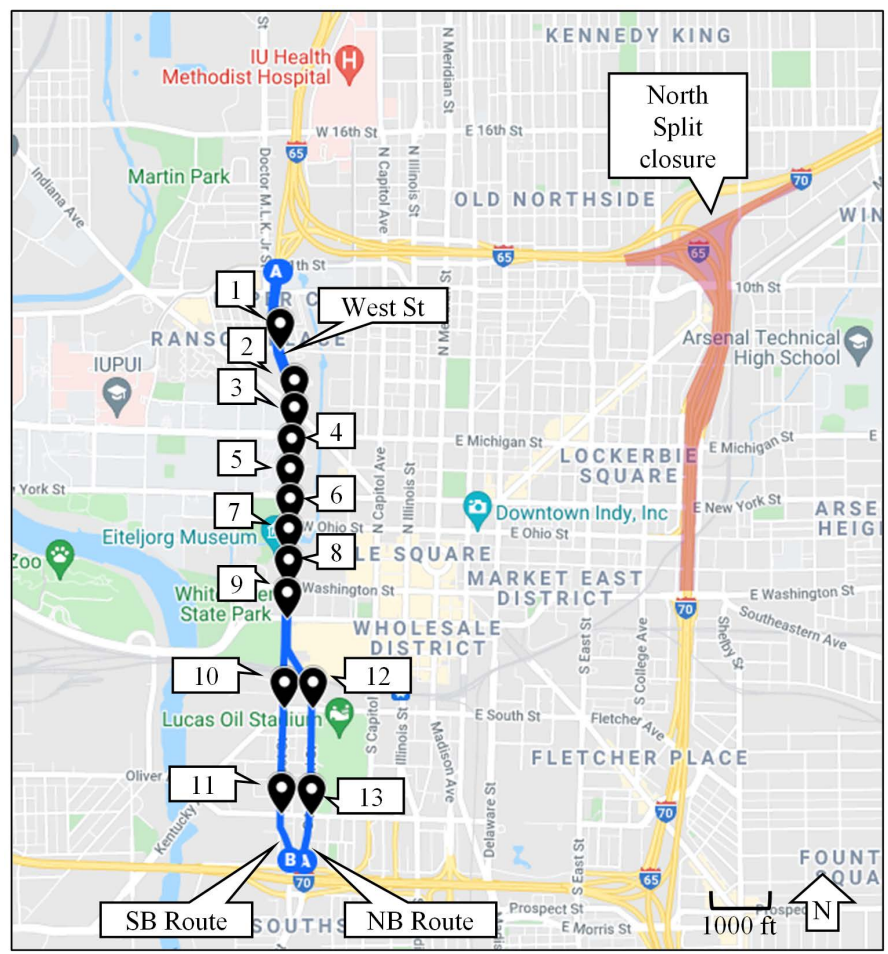

Figure 1. North split closure and West St intersections (Map data: Google).

Table 1. West St analyzed intersections.

\begin{tabular}{ccc}
\hline ID & Intersection Name & Direction of Travel \\
\hline 1 & West St @ Clair St & SB \& NB \\
2 & West St @ Indiana Ave & SB \& NB \\
3 & West St @ Michigan St & SB \& NB \\
4 & West St @ Vermont St & SB \& NB \\
5 & West St @ New York St & SB \& NB \\
6 & West St @ Ohio St & SB \& NB \\
7 & West St @ Robert D. Orr Plaza & SB \& NB \\
8 & West St @ Washington St & SB \& NB \\
9 & West St @ Maryland St & SB \& NB \\
10 & West St @ South St & SB \\
11 & West St @ McCarty & SB \\
12 & Missouri St @ South St & NB \\
13 & Missouri St @ McCarty St & NB \\
\hline
\end{tabular}

\section{Data Description}

Private sector CV trajectory data for the weekdays between May 3rd and July 16th, 2021was used in this study. The CV trajectory data consists of individual vehicle waypoints with a reporting interval of 3 seconds and a positional accuracy of a 1.5-meter radius. Every waypoint has the following attributes: GPS lo- 
cation, timestamp, speed, heading, and an anonymous unique trajectory identifier. During the May 3rd-July 16th, 2021 period, approximately 28 billion CV records were ingested for the entire state of Indiana for their real-time interstate and traffic signal monitoring program. For this study, approximately 130 thousand trajectories and 2 million GPS points that traversed the 13 intersections shown in Figure 1 were extracted from the Indiana dataset for further analysis.

\section{Indiana Traffic Signal Performance Monitoring}

In early 2020, a traffic signal performance measure monitoring program was implemented in the state of IN. As of July 2021, over 650 intersections of interest are analyzed daily using only CV trajectory data. The vast majority of these signals are in the great Indianapolis, IN area. Sampled volumes, Split Failures (SF), Downstream Blockage (DSB), Arrivals on Green (AOG), and Level of Service (LOS) are calculated for each location based on the methods presented in [25] [26]. New intersections are added to the portfolio by specifying the center of the intersection as an input to automatically assign movements to the trajectories. The details of that automated movement assignment are described in [30].

Figure 2(a) shows over 500 intersections in Indianapolis' metropolitan area which performance measures are updated daily. Callout i shows more than 100 local intersections in downtown Indianapolis that were added to the monitoring program in anticipation of the north split closure. Performance measures for the 13 intersections studied in this paper (Figure 2(b), callout ii) were retrieved from the results produced by the monitoring program.

In the following section, the diversions impact on the studied intersections is presented.

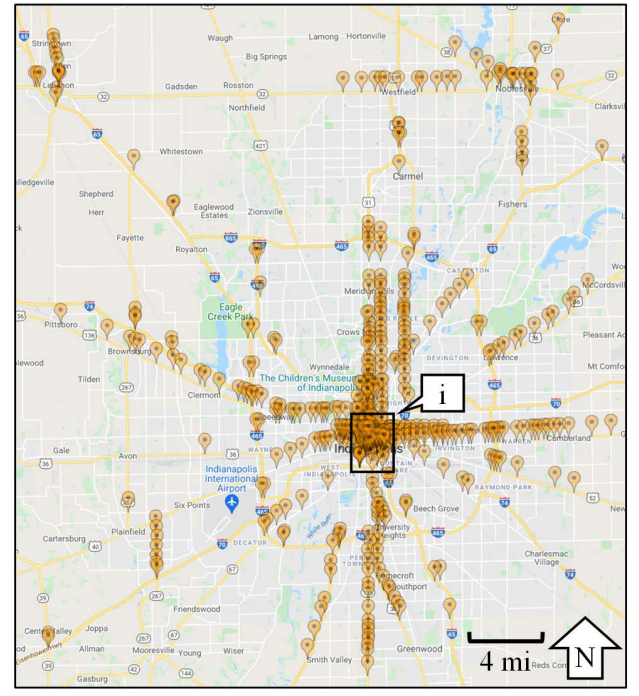

(a)

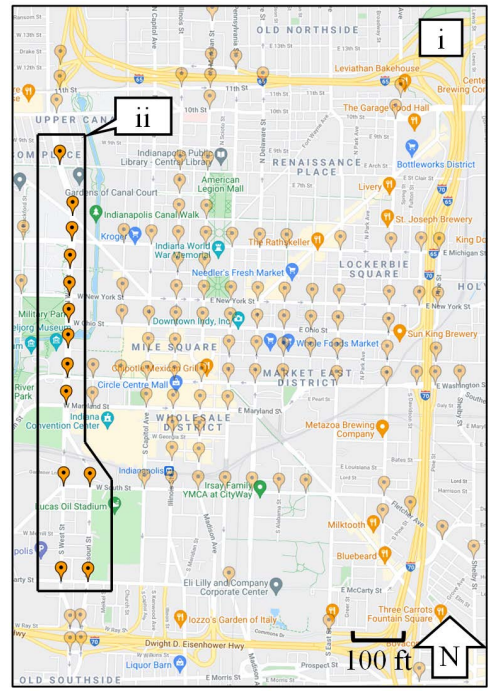

(b)

Figure 2. Location of intersections of interest for performance monitoring in IN (Map data: Google). (a) 502 intersections in Indianapolis metropolitan area; (b) 116 intersections in downtown Indianapolis. 


\section{Interstate Diversion Impact}

The following points are covered in this section:

1) A summary on the change in performance measures by Time-of-Day (TOD), before and after the North Split closure;

2) Changes in sampled volume;

3) Changes in corridor-wide trajectory patterns;

4) Changes in corridor-wide traffic signal performance measures on an intersection-by-intersection basis;

5) Changes in travel-time.

\subsection{Summary Performance Measures by Time-of-Day}

Figure 3 and Figure 4 show the summary of 5 performance measures by TOD, for vehicles traveling SB on West St, one week before (Figure 3), and one week after (Figure 4) the North Split closure. Additional details on how to interpret the graphics are provided below:

- Figure 3(a) and Figure 4(a): Percentage of sampled vehicles arriving on green [25] [26]. AOG is useful when assessing the level of progression at a particular location. Comparing these two figures, one can see a substantial decrease in arrivals on green during the PM peak period.

- Figure 3(b) and Figure 4(b): Percentage of vehicles experiencing split failures [25] [26]. This is a critical measurement that quantifies the occasions in which the traffic signal did not provide enough split (green) time for the stored queue to discharge. High levels of split failures indicate that an approach is operating at overcapacity. Comparing these two figures, one can see a substantial increase in split failures between the 15:00 and 18:00 hrs.

- Figure 3(c) and Figure 4(c): Percentage of vehicles experiencing downstream blockage [25] [26]. DSB is an important indicator that describes the level at which an adjacent intersection is affecting the progression at the studied location. Comparing these two figures, one can see a substantial increase in downstream blockage during the PM period between the 15:00 and 18:00 hrs, as well as throughout most of the day at intersections 4 and 7 .

- Figure 3(d) and Figure 4(d): Traditional Highway Capacity Manual (HCM) Level of Service (LOS). LOS categorized a location based on the experienced control delay (Table 2) [24]. Even though LOS does not provide actionable information by itself, it provides practitioners with an understanding on the levels of delay. Comparing these two figures, one can see a very large increase in LOS/delay during the period between the 15:00 and 18:00 hrs.

- Figure 3(e) and Figure 4(e): Corridor-wide travel time. Longer trips are seen during the PM period.

In summary, all the presented performance measures worsened after the North Split closure, specially from 15:00 to the $18: 00 \mathrm{hrs}$. As this period seems the most critical, further analysis will focus on that time-range. 


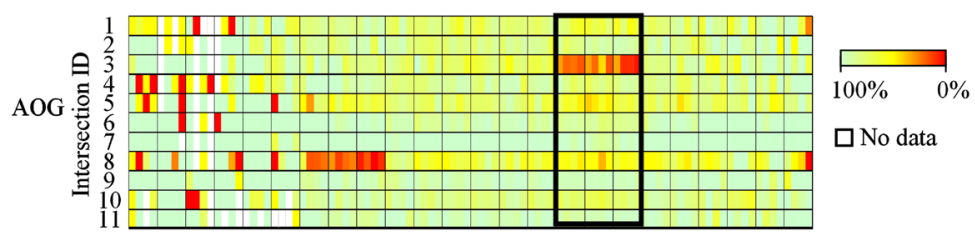

(a)
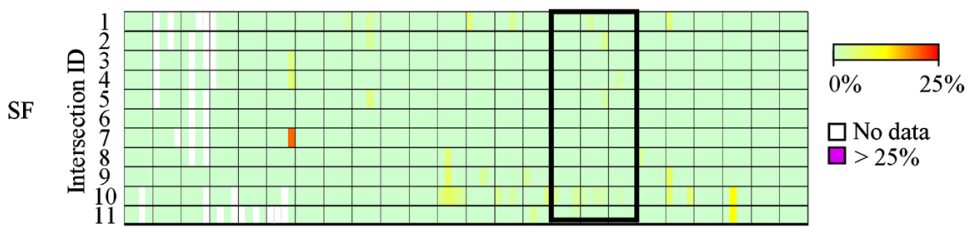

(b)
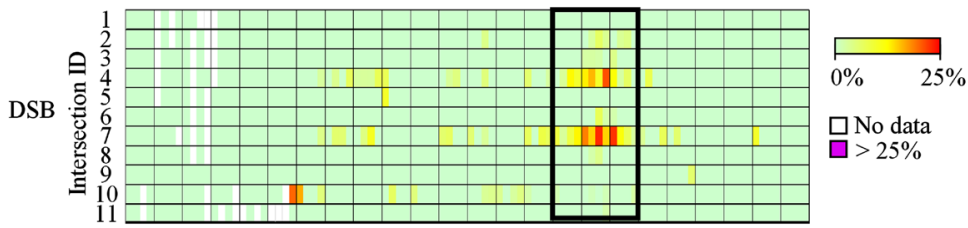

$\square$ No data

口> $>25 \%$

(c)

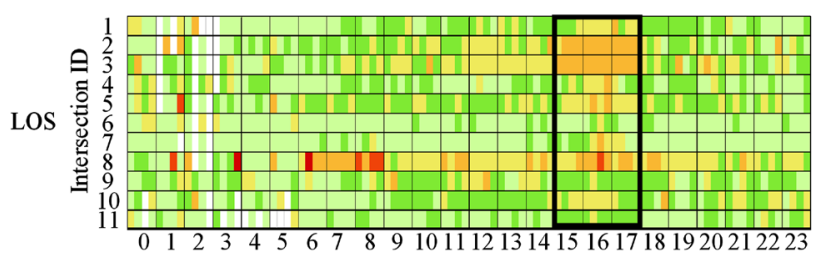

$\square \mathrm{A} \square \mathrm{D}$

$\square \mathrm{B} \square \mathrm{E}$

$\square \mathrm{C} \square \mathrm{F}$

(d)

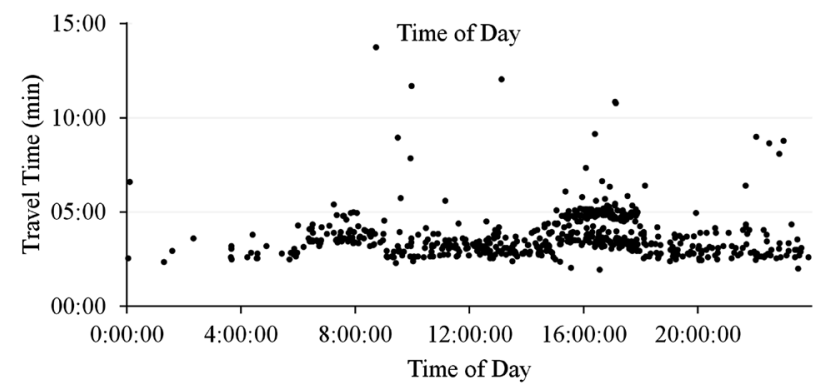

(e)

Figure 3. Signal performance measures and travel time one week before the North Split closure (May 10th-14th, 2021) for vehicles traveling SB: (a) Arrivals on green (AOG); (b) Split failures (SF); (c) Downstream blockage (DSB); (d) Level of service (LOS); (e) Travel time.

Table 2. HCM level of service criteria for signalized intersections [24].

\begin{tabular}{ccc}
\hline $\begin{array}{c}\text { Level of } \\
\text { Service }\end{array}$ & $\begin{array}{c}\text { Average Control Delay } \\
(\text { sec/vehicle })\end{array}$ & Description \\
\hline A & $\leq 10$ & Free Flow \\
B & $>10-20$ & Stable Flow (slight delay) \\
C & $>20-35$ & Stable Flow (acceptable delays) \\
D & $>35-55$ & Approaching Unstable Flow (tolerable delay) \\
E & $>55-80$ & Unstable Flow (intolerable delay) \\
F & $>80$ & Forced Flow (congested and queues fail to clear) \\
\hline
\end{tabular}



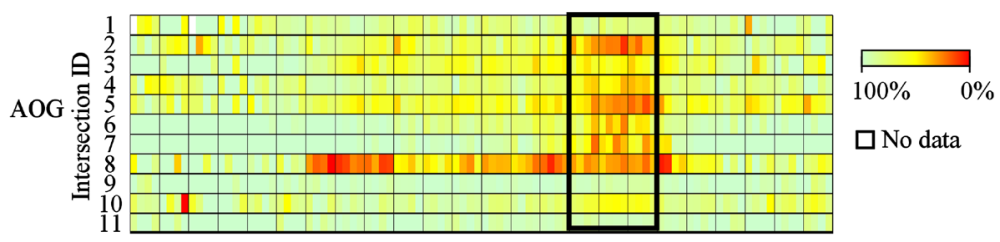

$\square$ No data

(a)
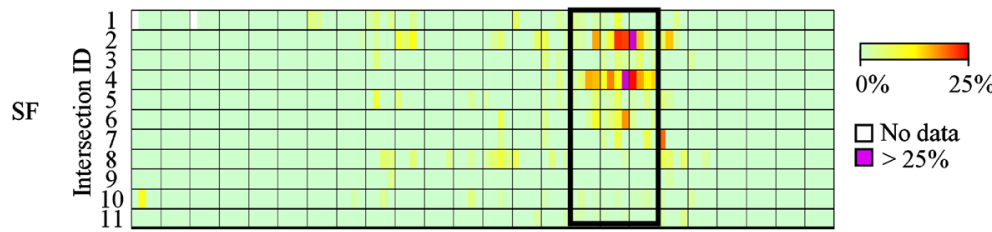

(b)
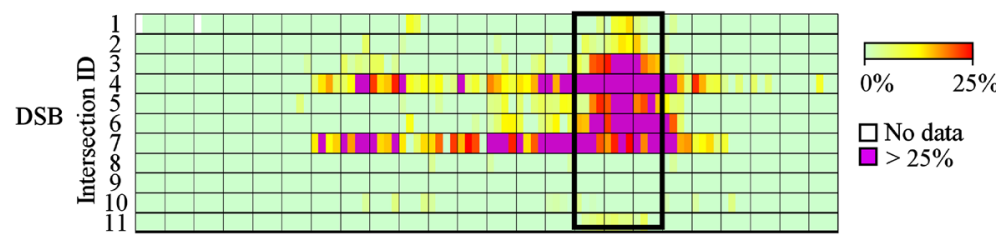

(c)

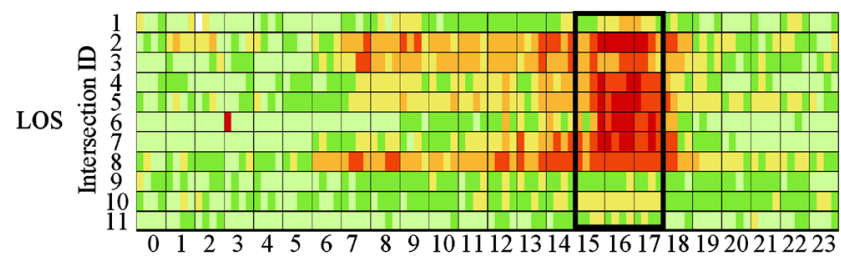

$\square \mathrm{A} \square \mathrm{D}$

$\square \mathrm{B} \square \mathrm{E}$

$\square \mathrm{C} \square \mathrm{F}$

(d)

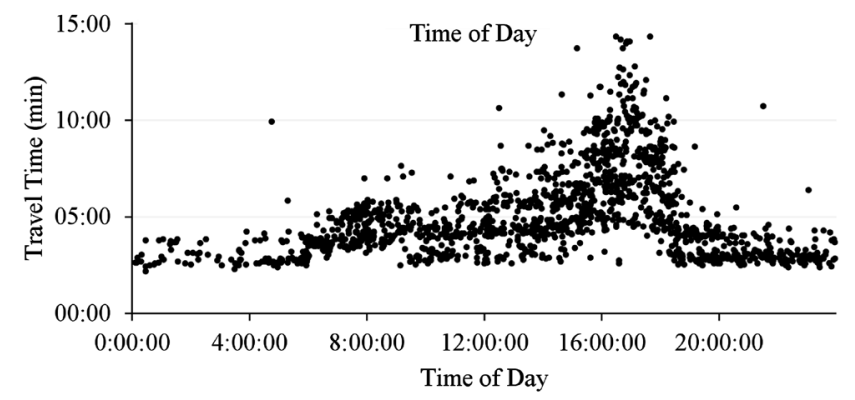

(e)

Figure 4. Signal performance measures and travel time one week after the North Split closure (May 17th-21st, 2021) for vehicles traveling SB: (a) Arrivals on Green (AOG); (b) Split Failures (SF); (c) Downstream Blockage (DSB); (d) Level of Service (LOS); (e) Travel time.

\subsection{Volumes}

As the 214,000 vehicles that used the North Split on a daily basis have to travel using alternative routes, a significant increase in the studied location's volumes is expected. Figure 5 shows the weekday weekly change in sampled CV volumes through the arterial from the 15:00 to the 18:00 hrs. Volumes just after the start of the North Split closure increased 148\% (from 54 to 134) for vehicles traveling SB and $455 \%$ (from 11 to 61 ) for vehicles traveling NB. Callouts i and ii are the weeks in which Memorial Day and the Independence Day were observed. 


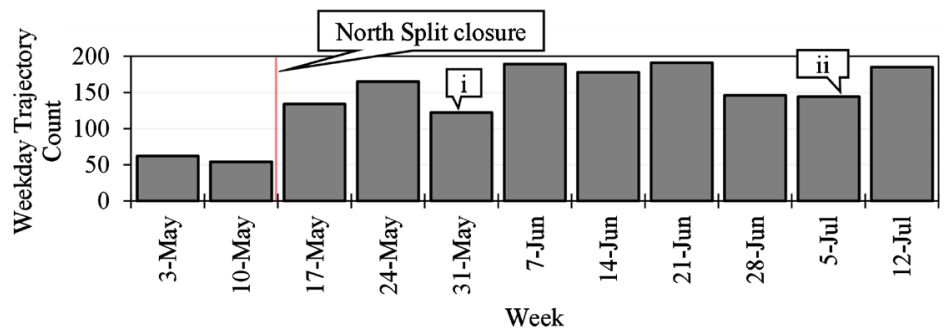

(a)

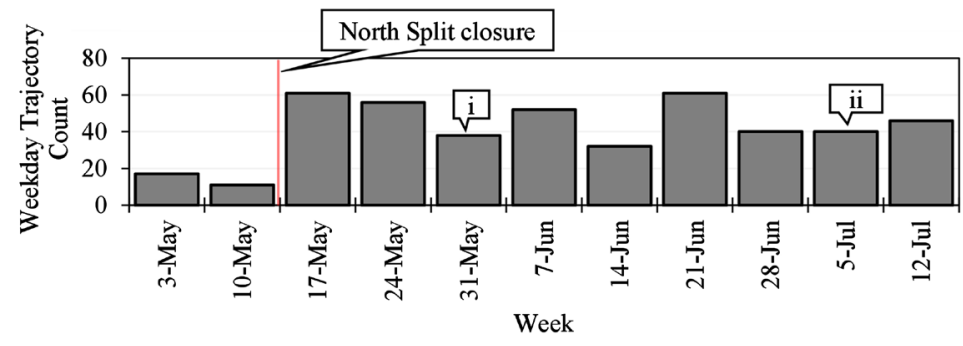

(b)

Figure 5. Weekday weekly trajectory counts from 15:00 to 18:00 hrs. (a) Southbound; (b) Northbound.

\subsection{Corridor-Wide Trajectories and Performance Measures by Intersection}

To better illustrate the operational dynamics at the studied intersections, trajectories of vehicles traveling SB through are plotted in Figure 6(a) (week before the beginning of the closure) and Figure 6(b) (week after the beginning of the closure). Next to the trajectories, downstream blockage, split failures, and arrivals on green results are displayed. The performance measures are placed in such a way that they match the segment of the trajectories which they represent (AOG and SF for the upstream section, and DSB for the downstream section). From performing a before and after qualitative comparison, the following points can be stated:

- By comparing Figure 6(a) and Figure 6(b), not only the increase in volume is noticeable, but also the increment in the number of stops and longer time required to transverse the corridor.

- By comparing Figure 6(c) and Figure 6(d), significant increments on downstream blockage occurred from intersections 3 to 7 . However, this critical problem seems to abruptly end after intersection 8 . This suggests that the downstream blockage identified at upstream locations may be a consequence of intersection 8 having queue spillback. If that is the case, by fixing the congestion at intersection 8 , the state of operation at the upstream locations could be improved as well.

- By comparing Figure 6(e) and Figure 6(f), it is clear that an important increase in split failures at intersections 2 and 4 occurred. However, as intersection 4 also showed significant downstream blockage, this is not necessarily an indication that the location is operating at overcapacity, but there is a possibility that its split failures are a result of downstream queue spillback. 


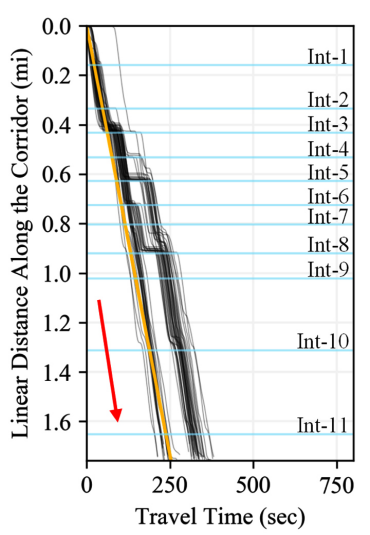

(a)

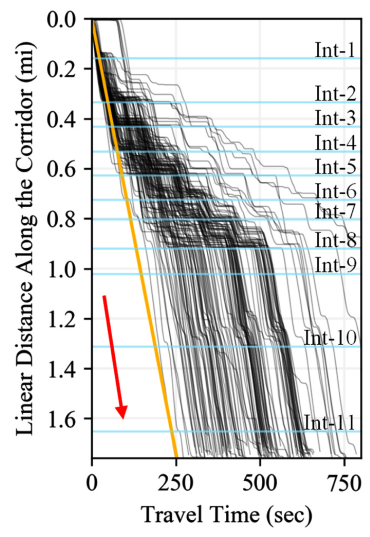

(b)

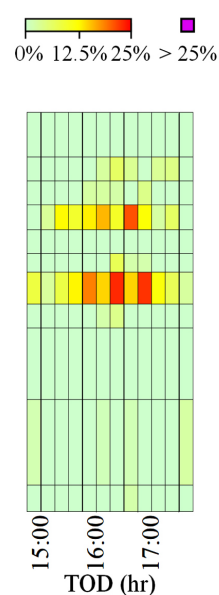

(c)

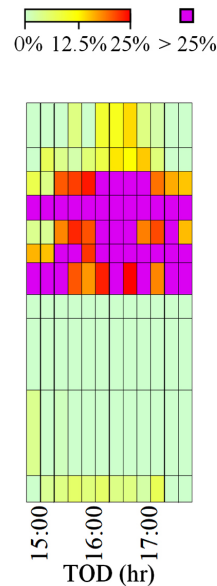

(d)

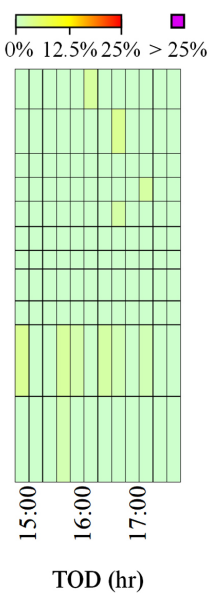

(e)

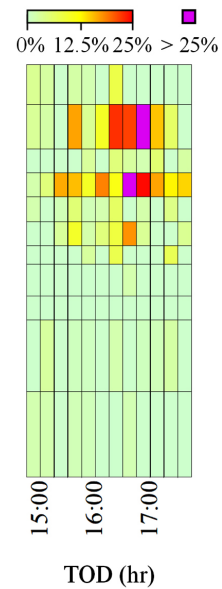

(f)

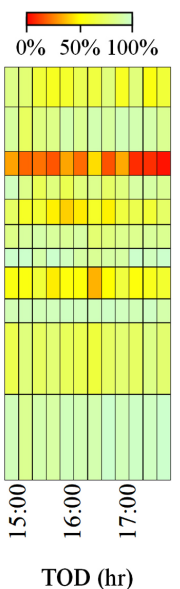

(g)

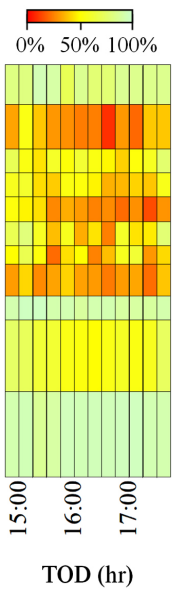

(h)

Figure 6. SB corridor-wide trajectories and performance measures from 15:00 to 18:00 hrs. one week before and one week after the North Split closure. (a) Corridor-wide trajectories: May 10th-May 14th; (b) Corridor-wide trajectories: May 17th-May 21st; (c) DSB: May 10th-May 14th; (d) DSB: May 17th-May 21st; (e) SF: May 10th-May 14th; (f) SF: May 17th-May 21st; (g) AOG: May 10th-May 14th; (h) AOG: May 17th-May 21st.

- By comparing Figure 6(g) and Figure 6(h), a general decline in arrivals on green is appreciated, specially from intersection 2 to 8 .

In addition to the corridor-wide trajectory plots, line graphs showing how critical split failure and downstream blockage vary through time provide valuable tools to identify where the challenges lay. Figure 7 shows weekday weekly split failures and downstream blockage results for the weeks from May 3rd to July 12th, 2021. Figure 7(a) quantitatively illustrates how intersections 2 and 4 had the highest increase in split failures after the North Split closure, which is an indication that there are challenges when trying to discharge waiting queues. Figure 7(b) shows that intersections 3 to 7 have a significant increase in downstream blockage. As intersection 4 experienced a significant increase both in split failures and downstream blockage, the cause of vehicles not being discharged after a traffic signal cycle length (split failure) is not necessarily a lack of split time, 


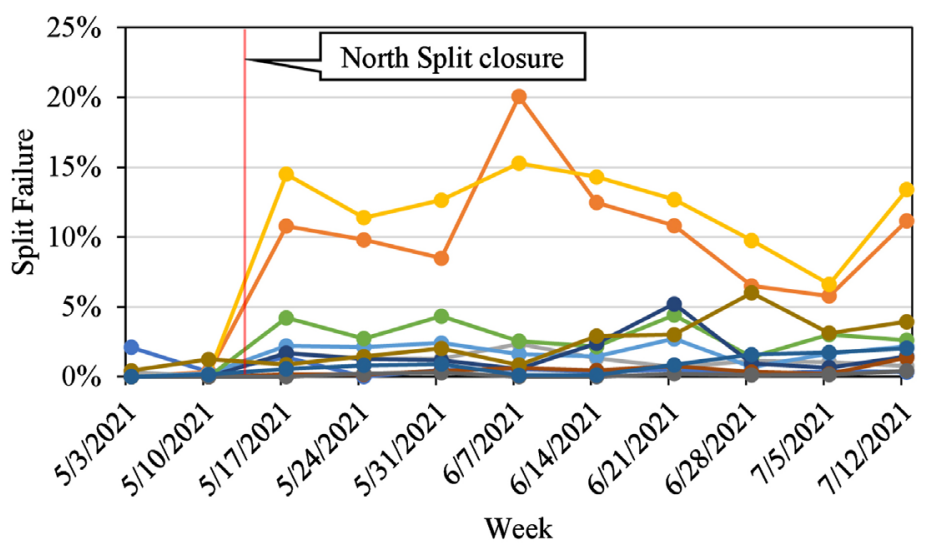

(a)

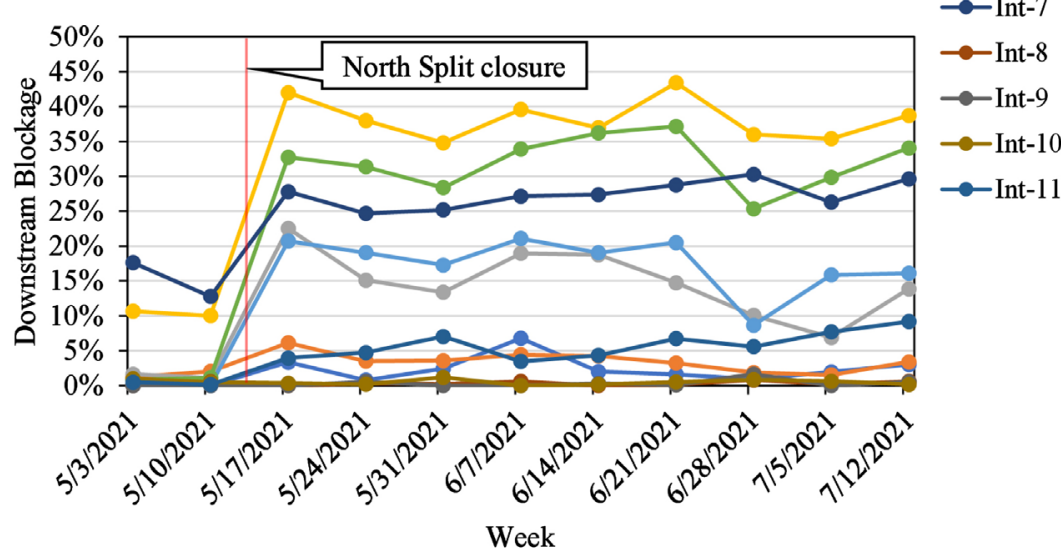

(b) $\longrightarrow$ Int-1

$\rightarrow-$ Int-3

$\rightarrow-$ Int-4

$\rightarrow$ Int-5

- Int-6

$\rightarrow$ Int-7

$\rightarrow-$ Int-8

- - Int-9 t-11
- Int-10

Figure 7. SB weekday weekly operational performance before and after the North Split closure from 15:00 to 18:00 hrs. (a) Percentage of sampled vehicles experiencing split failures; (b) Percentage of sampled vehicles experiencing downstream blockage.

but possibly progression blockage by the downstream spilling queue (downstream blockage).

\subsection{Travel Times}

A valuable, and commonly used metric to assess the performance of a corridor is travel time. An effective way of analyzing the travel time experienced by traveling vehicles is by generating Cumulative Frequency Distribution (CFD) plots. In general, a good-performing arterial will show a vertical line (which is an indication of reliability) with the minimum possible travel time (near free flow).

Figure 8 shows corridor travel time CFDs for the analysis period. For the SB trajectories (Figure 8(a)), travel time increased noticeably since the May 17th week (right after the start of the closure). In fact, the median travel time increased from 5.4 minutes before the closure to 8.5 minutes after the closure. Furthermore, a reduction in travel time reliability can be inferred by the reduction in slope of the lines, indicating an increase in travel-time variation. For the NB trajectories, not significant changes can be seen from Figure 8(b). 


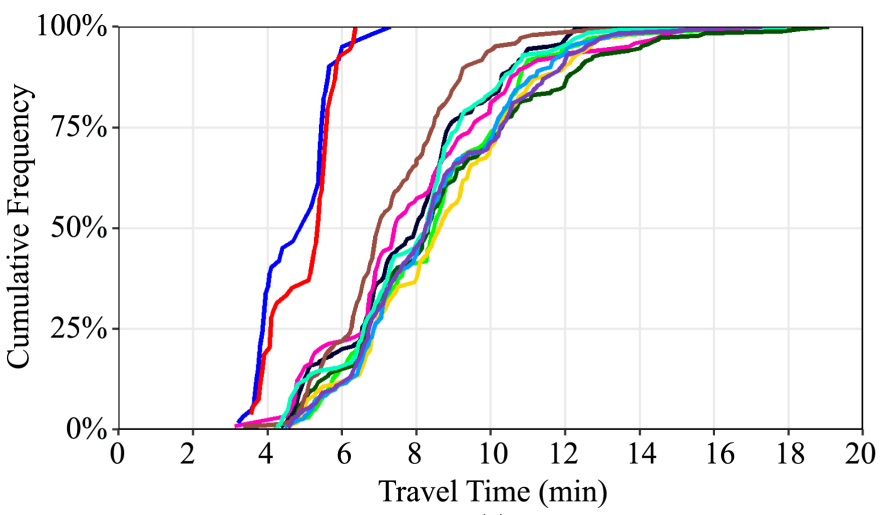

(a)

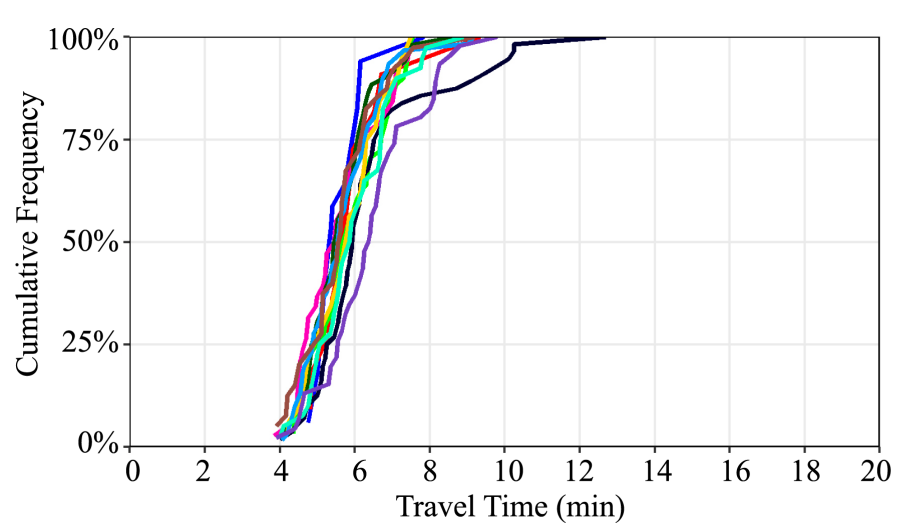

(b)
- 5/3/2021

- 5/10/2021

- 5/17/2021

$-5 / 24 / 2021$
$-5 / 31 / 2021$

- $6 / 7 / 2021$

- $6 / 14 / 2021$

- $6 / 21 / 2021$

- 6/28/2021

- $7 / 5 / 2021$

- 7/12/2021

Figure 8. Corridor-wide Travel Time Cumulative frequency distribution before and after the North Split closure from 15:00 to 18:00 hrs. (a) Southbound; (b) Northbound.

\section{Results}

Corridor-wide weighted average DSB, SF, and AOG results are shown in Figure 9. As expected, most performance measures worsened significantly after the North Split closure, specifically for the SB direction of travel. The maximum changes in performance for before and after the closure are $10 \%$ increase in DSB, $3 \%$ increase in SF, and a 16\% decrease in AOG (all for the SB direction).

Results for the corridor travel time are presented in Figure 10. For the SB direction of travel, the Interquartile Range (IQR) increased by up to $140 \%$, and the median travel time rose $74 \%$ when comparing before and after the closure. For the NB direction of travel, IQR increased by up to $83 \%$, and the median travel time rose $19 \%$.

\section{Discussion and Conclusions}

This study estimated traffic signal performance measures from CV trajectory data with a 3-second reporting interval to assess the effects that Indianapolis' North Split closure on May 15th, 2021, had on a 13-intersection segment of West St., an alternative route. From the over 130,000 trajectories analyzed during an 11-week period from 15:00-18:00 hrs, the following results were observed (Figure 5, Figure 9, and Figure 10). 


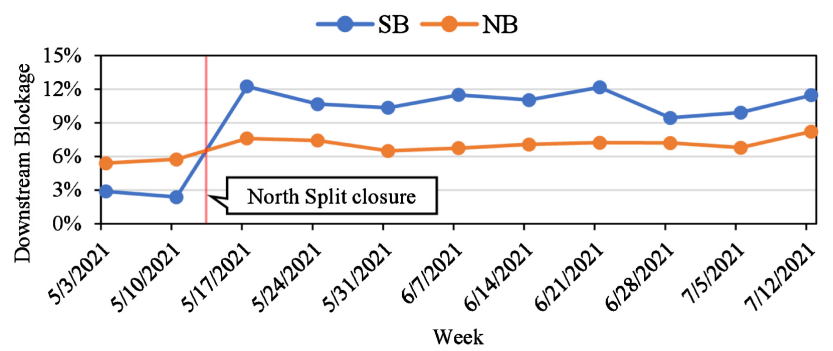

(a)

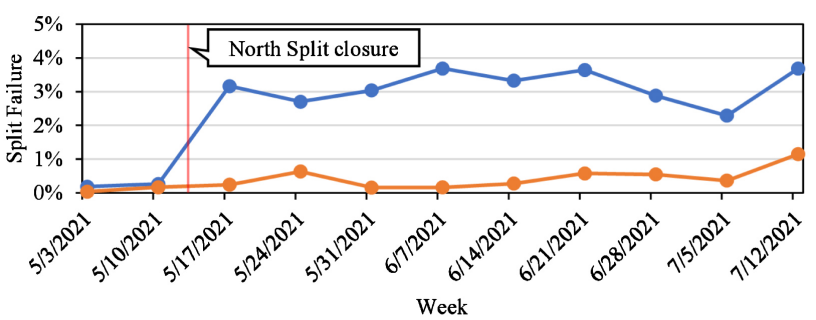

(b)

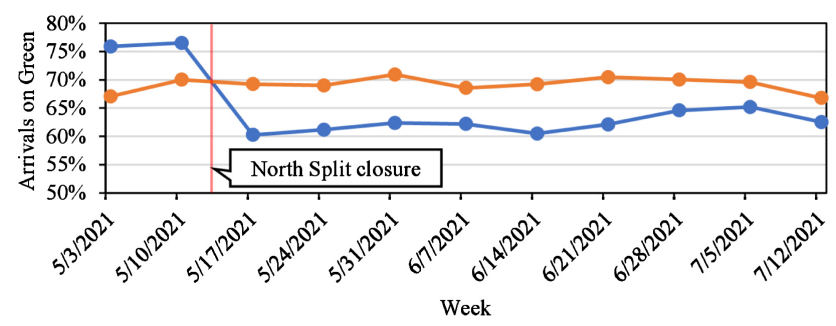

(c)

Figure 9. Corridor-wide traffic signal performance measures from 15:00 to 18:00 hrs. (a) Percentage of sampled vehicles experiencing downstream blockage; (b) Percentage of sampled vehicles experiencing split failures; (c) Arrivals on green.

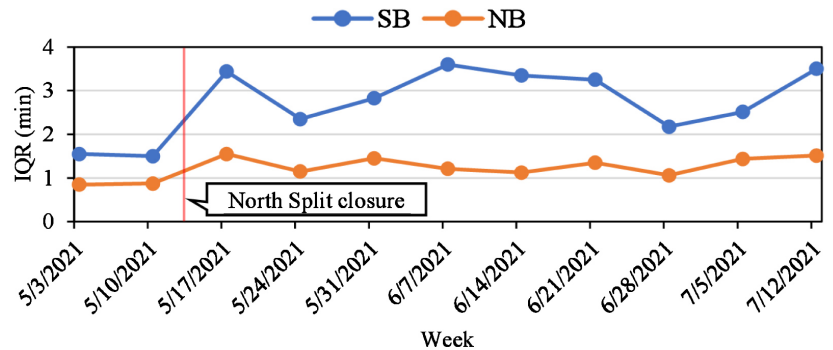

(a)

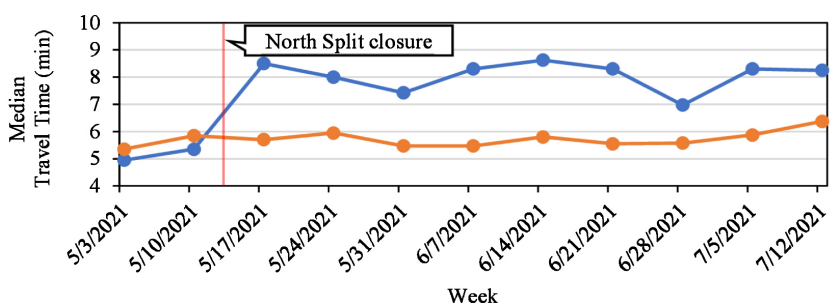

(b)

Figure 10. Interquartile range (IQR) and median travel time from 15:00 to 18:00 hrs. (a) Travel time interquartile range; (b) Median travel time. 
- $455 \%$ increase on sampled volumes, which indicates a significant increase in demand on the arterial;

- $74 \%$ increase in median travel time.

Specific operational failure modes that contributed to this increase in travel time include:

- $3 \%$ increase on split failures, indicating an increment of traffic signals operating at overcapacity;

- $10 \%$ increase on downstream blockage, indicating there was queue spillback from downstream traffic signals;

- $16 \%$ decrease on arrivals on green, indicating there were opportunities to improve traffic signal coordination.

From Figure 6, intersection 8 (Washington St) was identified as a location that influences the operational state at upstream intersections. This is an example of how agencies can use these dashboards to identify critical intersections that affect the entire network.

The calculated performance measures can be applied to any location in the world where connected vehicle trajectory data is available. Additionally, the trajectory movement identification method utilized to calculate performance measures does not require road geofencing, which enhances scalability. With this new approach, agencies could analyze hundreds of traffic signals in a time and cost-effective manner without the need for any vehicle sensing equipment.

\section{Acknowledgements}

Trajectory data for weekdays between May 3rd and July 16th, 2021 used in this study, was provided by Wejo Data Services, Inc. This work was supported in part by the Joint Transportation Research Program and Pooled Fund Study (TPF-5(377)) led by the Indiana Department of Transportation (INDOT) and supported by the state transportation agencies of California, Connecticut, Georgia, Minnesota, North Carolina, Ohio, Pennsylvania, Texas, Utah, Wisconsin, plus the City of College Station, Texas, and the FHWA Operations Technical Services Team. The contents of this paper reflect the views of the authors, who are responsible for the facts and the accuracy of the data presented herein, and do not necessarily reflect the official views or policies of the sponsoring organizations. These contents do not constitute a standard, specification, or regulation.

\section{Conflicts of Interest}

The authors declare no conflicts of interest regarding the publication of this paper.

\section{References}

[1] Schrank, D., Albert, L., Eisele, B. and Lomax, T. (2021) 2021 Urban Mobility Report. Texas A\&M Transportation Institute, College Station.

[2] Federal Highway Administration, Office of Operations (2017) Making Work Zones Work Better. https://ops.fhwa.dot.gov/aboutus/one_pagers/wz.htm 
[3] Lochrane, T.W.P., Al-Deek, H., Paracha, J. and Scriba, T. (2013) Understanding Driver Behavior in Work Zones. Public Roads, 76, p. https://www.fhwa.dot.gov/publications/publicroads/13marapr/04.cfm

[4] Li, X., Cao, Y., Zhao, X. and Xie, D. (2015) Drivers' Diversion from Expressway under Real Traffic Condition Information Shown on Variable Message Signs. KSCE Journal of Civil Engineering, 19, 2262-2270. https://doi.org/10.1007/s12205-014-0692-y

[5] Gan, H. and Ye, X. (2012) Urban Freeway Users' Diversion Response to Variable Message Sign Displaying the Travel Time of Both Freeway and Local Street. IET Intellgent Transport Systemsgent, 6, 78-86. https://doi.org/10.1049/iet-its.2011.0070

[6] Gan, H. (2013) Investigation of Driver Response to the Enhanced Urban Freeway Variable Message Sign Information. KSCE Journal of Civil Engineering, 17, 1455-1461. https://doi.org/10.1007/s12205-013-0231-2

[7] Jou, R.C., Lam, S.H., Liu, Y.H. and Chen, K.H. (2005) Route Switching Behavior on Freeways with the Provision of Different Types of Real-Time Traffic Information. Transportation Research Part A: Policy and Practice, 39, 445-461. https://doi.org/10.1016/j.tra.2005.02.004

[8] Chorus, C.G., Molin, E.J.E. and van Wee, B. (2006) Use and Effects of Advanced Traveller Information Services (ATIS): A Review of the Literature. Transport Reviews, 26, 127-149. https://doi.org/10.1080/01441640500333677

[9] Petrella, M. and Lappin, J. (2004) Comparative Analysis of Customer Response to Online Traffic Information in Two Cities Los Angeles, California, and Seattle, Washington. Transportation Research Record, 1886, 10-17. https://doi.org/10.3141\%2F1886-02

[10] Yim, Y., Khattak, A.J. and Raw, J. (2002) Traveler Response to New Dynamic Information Sources: Analyzing Corridor and Areawide Behavioral Surveys. Transportation Research Record, 1803, 66-75. https://doi.org/10.3141\%2F1803-10

[11] Liang, Z. and Wakahara, Y. (2014) Real-Time Urban Traffic Amount Prediction Models for Dynamic Route Guidance Systems. EURASIP Journal on Wireless Communications and Networking, 2014, Article No. 85. https://doi.org/10.1186/1687-1499-2014-85

[12] Memarian, A., Rosenberger, J.M., Mattingly, S.P., Williams, J.C. and Hashemi, H. (2019) An Optimization-Based Traffic Diversion Model during Construction Closures. Computer-Aided Civil and Infrastructure Engineering, 34, 1087-1099. https://doi.org/10.1111/mice.12491

[13] Effinger, J., Horowitz, A.J., Liu, Y. and Shaw, J. (2013) Bluetooth Vehicle Reidentification for Analysis of Work Zone Diversion. Presented at 92nd Annual Meeting of Transportation Research Board, Washington DC, 13-17 January 2013, 1-15.

[14] Hainen, A.M., Wasson, J.S., Hubbard, S.M.L., Remias, S.M., Farnsworth, G.D. and Bullock, D.M. (2011) Estimating Route Choice and Travel Time Reliability with Field Observations of Bluetooth Probe Vehicles. Transportation Research Record, 2256, 43-50. https://doi.org/10.3141\%2F2256-06

[15] Haseman, R.J., Wasson, J.S. and Bullock, D.M. (2010) Real-Time Measurement of Travel Time Delay in Work Zones and Evaluation Metrics Using Bluetooth Probe Tracking. Transportation Research Record, 2169, 40-53. https://doi.org/10.3141\%2F2169-05

[16] McNamara, M., Li, H., Remias, S., Richardson, L., Cox, E., Horton, D., et al. (2015) Using Real-Time Probe Vehicle Data to Manage Unplanned Detour Routes. ITE Journal, 85, 32-37. 
[17] Day, C., Bullock, D.M., Li, H., Remias, S.M., Hainen, A.M., Freije, R.S., et al. (2014) Performance Measures for Traffic Signal Systems: An Outcome-Oriented Approach. Purdue University, West Lafayette. https://doi.org/10.5703/1288284315333

[18] Federal Highway Administration (FHWA) (2019) Every Day Counts: An Innovation Partnership with States. Federal Highway Administration, Washington DC.

[19] Day, C., Bullock, D., Li, H., Lavrenz, S., Smith, W.B.B. and Sturdevant, J. (2015) Integrating Traffic Signal Performance Measures into Agency Business Processes. Purdue University, West Lafayette. https://doi.org/10.5703/1288284316063

[20] Zhao, Y., Zheng, J., Wong, W., Wang, X., Meng, Y. and Liu, H.X. (2019) Estimation of Queue Lengths, Probe Vehicle Penetration Rates, and Traffic Volumes at Signalized Intersections Using Probe Vehicle Trajectories. Transportation Research Record, 2673, 660-670. https://doi.org/10.1177\%2F0361198119856340

[21] Cetin, M. (2012) Estimating Queue Dynamics at Signalized Intersections from Probe Vehicle Data: Methodology Based on Kinematic Wave Model. Transportation Research Record, 2315, 164-172. https://doi.org/10.3141\%2F2315-17

[22] Li, H., Mackey, J., Luker, M., Taylor, M. and Bullock, D.M. (2019) Application of High-Resolution Trip Trace Stitching to Evaluate Traffic Signal System Changes. Transportation Research Record, 2673, 188-201. https://doi.org/10.1177\%2F0361198119841043

[23] Zhang, K., Jia, N., Zheng, L. and Liu, Z. (2019) A Novel Generative Adversarial Network for Estimation of Trip Travel Time Distribution with Trajectory Data. Transportation Research Part C: Emerging Technologies, 108, 223-244. https://doi.org/10.1016/j.trc.2019.09.019

[24] Transportation Research Board (TRB) (2010) Highway Capacity Manual 2010. National Research Council (NRC), Washington DC.

[25] Saldivar-Carranza, E., Li, H., Mathew, J., Hunter, M., Sturdevant, J. and Bullock, D.M. (2021) Deriving Operational Traffic Signal Performance Measures from Vehicle Trajectory Data. Transportation Research Record, Article ID: 036119812110067. https://doi.org/10.1177\%2F03611981211006725

[26] Saldivar-Carranza, E.D. (2021) Scalable Operational Traffic Signal Performance Measures from Vehicle Trajectory Data. Purdue University, West Lafayette. https://doi.org/10.25394/PGS.14371691.v1

[27] Waddell, J.M., Remias, S.M. and Kirsch, J.N. (2020) Characterizing Traffic-Signal Performance and Corridor Reliability Using Crowd-Sourced Probe Vehicle Trajectories. Journal of Transportation Engineering, Part A: Systems, 146, Article ID: 04020053. https://doi.org/10.1061/JTEPBS.0000378

[28] Huang, J., Li, G., Wang, Q. and Yu, H. (2013) Real Time Delay Estimation for Signalized Intersection Using Transit Vehicle Positioning Data. 2013 13th International Conference on ITS Telecommunications, Tampere, 5-7 November 2013, 216-221. https://doi.org/10.1109/ITST.2013.6685548

[29] Day, C.M., Li, H., Richardson, L.M., Howard, J., Platte, T., Sturdevant, J.R., et al. (2017) Detector-Free Optimization of Traffic Signal Offsets With Connected Vehicle Data. Transportation Research Record: Journal of the Transportation Research Board, 2620, 54-68. https://doi.org/10.3141\%2F2620-06

[30] Saldivar, E., Carranza, D., Li, H. and Bullock, D.M. (2021) Identifying Vehicle Turning Movements at Intersections from Trajectory Data. IEEE Xplore. 